\title{
Comparison of the adrenalytic activity of mitotane and a methylated homolog on normal adrenal cortex and adrenal cortical carcinoma
}

\author{
David E. Schteingart, Joseph E. Sinsheimer, Raymond E. Counsell, Gerald D. Abrams, Nancy McClellan, \\ Tanya Djanegara, Jennifer Hines, Nongluck Ruangwises, Ricardo Benitez, and Linda L. Wotring
}

Departments of Internal Medicine, Pharmacology, and Pathology, Medical School and College of Pharmacy, University of Michigan, Ann Arbor, MI 48109, USA

Received 13 August 1992/Accepted 26 October 1992

Summary. Mitotane is an important adrenalytic drug for the treatment of adrenal cancer whose use is limited by toxicity. Reports from another laboratory indicated that a methylated homolog of Mitotane (Mitometh) tested in guinea pigs possessed comparable adrenalytic activity but was less toxic than Mitotane. This observation prompted us to undertake a comparative study of these two drugs on the basis that Mitometh may be a superior agent for the treatment of adrenal cancer. Preliminary studies in guinea pigs failed to show a significant adrenalytic effect for either Mitotane or Mitometh. Thus, we extended the study to 13 mongrel dogs weighing $12-15 \mathrm{~kg}$ that were treated daily with Mitometh or Mitotane $(50-100 \mathrm{mg} / \mathrm{kg}$ ) for 6 or 12 days. Cortisol decreased to undetectable levels and adrenocorticotropic hormone (ACTH) rose to 10 times the baseline levels within $72 \mathrm{~h}$ in Mitotane-treated animals. Despite the achievement of similar drug levels, Mitometh treatment in dogs failed to suppress cortisol or increase ACTH. To determine whether these differences were due to differences in bioavailability, we measured the relative concentration of Mitotane and Mitometh in homogenates of adrenal cortex obtained from Mitotane- and Mitomethtreated dogs. The adrenal concentration of Mitometh determined in Mitometh-treated dogs was 5 times higher than the concentration of Mitotane measured in Mitotanetreated animals. Whereas the adrenal glands of Mitotanetreated dogs showed hemorrhage and necrosis, the Mitometh-treated animals showed no adrenal damage. Despite the lack of adrenalytic activity, Mitometh maintained its toxicity as demonstrated by microscopic evidence of hepatic necrosis and an increase in hepatic enzymes. The adrenalytic effects of both agents was also studied in vitro using a human functioning adrenal cortical carcinoma cell line, NCI-H295. Whereas Mitotane strongly suppressed cell growth, Mitometh had a weaker effect. We conclude

Correspondence to: David E. Schteingart, University of Michigan Medical Center, 5570 MSRB-II, Box 0678, 1150 West Medical Center Drive, Ann Arbor, MI 48 109-0678 that Mitometh is not likely to be effective in the therapy of adrenal cancer. Moreover, the results of this study are supportive of the view that metabolic transformation of Mitotane is in some way linked to its adrenalytic action.

\section{Introduction}

Mitotane [1-(o-chlorophenyl)-1-( $p$-chlorophenyl)-2,2-dichloroethane; $o, p^{\prime}$-DDD] is an adrenalytic drug used in the treatment of adrenal cancer and benign Cushing's syndrome whose application is limited by toxicity. Mitotane's activity appears to depend on its metabolism. In vitro studies [15] using adrenal cell mitochondria suggested that Mitotane's activity required metabolism and covalent binding to cell macromolecules, but this requirement had not been demonstrated in vivo. Jensen et al. [13] reported that in the guinea pig, Mitometh [1-(o-chlorophenyl)-1-( $p$ chlorophenyl)-2,2-dichloropropane], a methylated analog of Mitotane, was capable of inducing ultramicroscopic changes in adrenocortical cells similar to those caused by Mitotane but was not as toxic, making it an attractive candidate for use in adrenal cancer. Since Mitometh, in contrast to Mitotane, is incapable of forming the acid metabolite $o$-chlorophenyl- $p$-chlorophenyl acetic acid $\left(o, p^{\prime}\right.$ DDA), the studies by Jensen et al. seemed to negate the importance of metabolism of the $-\mathrm{CHCl}_{2}$ moiety as a requirement for the adrenalytic activity of Mitotane. To study the activity of Mitometh and its possible use in adrenal cancer, we compared the adrenalytic activity of Mitometh and Mitotane both in vivo in guinea pigs and dogs with normal adrenal function and in vitro on a functioning human adrenal cortical carcinoma cell culture.

\section{Materials and methods}

Compounds. Mitotane (USP grade) was obtained from Bristol Myers. Mitometh was synthesized using a modification of the procedure of 


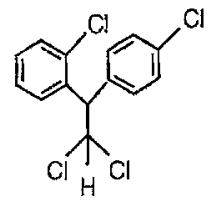

Mitotane $\left(o, p^{\prime}-D D D\right)$

Fig. 1. Chemical structures of Mitotane and Mitometh

Jensen et al. [13] (Fig. 1). The crude product was purified by column chromatography (silica with hexane). This afforded $5.33 \mathrm{~g}$ of a clear oil ( $85 \%$ ) that crystallized upon standing. Recrystallization from methanol gave a pure product with a melting point of $54^{\circ}-55^{\circ} \mathrm{C}$. The nuclear magnetic resonance of the crystalline product agreed with the values reported by Jensen and co-workers [13]. Thin-layer chromatography indicated a single spot $\left(R_{\mathrm{f}}, 0.29\right)$ in cyclohexane. The analytical data calculated for $\mathrm{C}_{15} \mathrm{H}_{12} \mathrm{Cl}_{4}$ were: $\mathrm{C}, 53.93 \%$; and $\mathrm{H}, 3.62 \%$. The values found were: $\mathrm{C}, 54.03 \%$; and $\mathrm{H}, 3.53 \%$. The final Mitometh product used in animal studies was found to be $97 \%$ pure by thermal analysis with the presence of $<0.6 \%$ Mitotane and $2.4 \%$ unsaturated Mitometh [1-(ochlorophenyl)-1-( $p$-chlorophenyl)-2-chloro-1-propene] as determined by gas chromatographic analysis.

Assays. Serum cortisol was measured by a solid-phase ${ }^{225}$ I radioimmunoassay (Coat-A-Count; Diagnostic Products). The sensitivity of this assay is $0.2 \mu \mathrm{g} / \mathrm{dl}$ and the specificity is $97 \%$ (the cross-reactivity with prednisolone is $46 \%$ and that with prednisone is $3.1 \%$ ).

Plasma adrenocorticotropic hormone (ACTH) levels were determined by radioimmunoassay (RIA) by the method of Vague et al. [27] using a very sensitive and specific antibody at a dilution of $1: 800,000$. This antibody has low cross-reactivity with other peptides and is capable of detecting ACTH in plasma at concentrations as low as $6 \mathrm{pg} / \mathrm{ml}$. Separation of free from bound hormone was carried out with a $1.5 \%$ charcoal suspension. The tracer was prepared using human ACTH 1-39 (Peninsula Laboratories) and iodinated with ${ }^{125} \mathrm{I}$ by the chloramine- $\mathrm{T}$ method [12]. Plasma samples were stored at $-80^{\circ} \mathrm{C}$ until assay with loss of less than $10 \%$ activity within 1 year. ACTH was measured in unextracted plasma and each sample was run in four dilutions. Quality-control studies were carried out with each assay using standard sera and carryover samples from previous assays with high, intermediate, and low ACTH concentrations. The coefficient of variation for this assay is $4.2 \% \pm 1.2 \%$ for $20 \%$ binding and $8.4 \% \pm 2.4 \%$ for $80 \%$ binding.

Serum and tissue levels of Mitotane and Mitometh were determined by gas chromatography (GC-EC). Serum levels were obtained at $2 \mathrm{~h}$ following the first daily drug dose. To $100-\mu l$ aliquots of serum, $10 \mu \mathrm{l}$ of an internal-standard methanol solution containing 1-(o-chlorophenyl)-1( $p$-chlorophenyl)-2,2-dichloroethylene ( $o, p^{\prime}$-DDE) at a concentration of $8.88-44.4 \mathrm{~g} / \mathrm{ml}$ was added. Standards were prepared using increasing concentrations of Mitotane or Mitometh in methanol solution, $100 \mu 1$ control plasma from sesame oil-treated dogs, and $10 \mu l o, p^{\prime}$-DDE in methanol as the internal standard. To both samples and standards, $100 \mu \mathrm{l}$ formic acid was added to denature proteins. Samples were extracted with $1.5 \mathrm{ml}$ high-performance liquid chromatography (HPLC)-grade hexane and centrifuged at $1700 \mathrm{~g}$ for $6 \mathrm{~min}$. Adrenal glands obtained from treated and control dogs anesthetized with sodium pentobarbital $(30 \mathrm{mg} / \mathrm{kg}$ ) were trimmed of fat and connective tissue and the cortex was separated and homogenized. The homogenate was extracted with ether/methanol and the extracts were combined, evaporated to dryness, and reconstituted in hexane for analysis; $10 \mu \mathrm{l} o, p^{\prime}$-DDE in methanol was added as the internal standard. Aliquots $(1 \mu \mathrm{l})$ of hexane supernatant of each sample and standard solutions and of the adrenal extract were injected into a Varian 3700 gas chromatograph equipped with a ${ }^{63} \mathrm{Ni}$ electron-capture detector and a glass column $(2 \mathrm{~m} \times 2 \mathrm{~mm}$ inside diameter) containing $3 \%$ OV-101 on gas-chrom Q (80-100 mesh). The conditions were: column temperature, $215^{\circ} \mathrm{C}$; injection temperature, $250^{\circ} \mathrm{C}$; and detector temperature, $300^{\circ} \mathrm{C}$. Nitrogen was used as the carrier gas. Peak/height ratios of Mitotane or Mitometh to $o, p^{\prime}$-DDE were used to establish the standard curve. Values for the unknown samples were read off the standard curve.

Measurement of serum aspartate aminotransferase (AST), alanine aminotransferase (ALT), cholesterol, and alkaline phosphatase was carried out using Beckman Autoanalyzer methods. AST and ALT are measured photometrically by the use of a reduced nicotinamide adenine dinucleotide (NADH)-coupled reaction; the alkaline phosphatase procedure uses $p$-nitrophenylphosphate ( $p$-NPP) as the substrate, carbonate-bicarbonate as the buffer, and glycerol as the phosphate acceptor.

In vivo studies. Studies were initially carried out in female Hartley guinea pigs weighing $300-400 \mathrm{~g}$ since Jensen et al. [13] had reported adrenalytic effects of Mitotane and Mitometh in this animal species. Because of the well-known adrenalytic effect of Mitotane, this drug was tested first. Oral treatment at levels of 150 and $300 \mathrm{mg} / \mathrm{kg}$ daily in corn-oil emulsion for 4 weeks failed to show any significant suppressive effect on cortisol levels or gross adrenal changes. It was also noted that Mitotane blood levels were barely measurable when obtained at $2 \mathrm{~h}$ following drug administration. These levels became easily measurable when the oral dose was increased to $1200 \mathrm{mg} / \mathrm{kg}$ daily. At this dose level, cortisol values did not decrease but the animals developed weight loss, diarrhea, lethargy, and alopecia. In view of the relatively poor absorption from the oral dose, Mitotane was reformulated in Tween- 80 and $0.9 \%$ saline for intraperitoneal (i. p.) injection. Better absorption and higher blood levels were noted when 150 and $300 \mathrm{mg} / \mathrm{kg}$ Mitotane were given as a single injection. Chronic administration of these two doses for a period of 2 weeks caused weight loss, diarrhea, lethargy, and alopecia, and all animals died before the completion of the study. Cortisol levels during treatment were elevated, suggesting stress effects.

Since the i. p. injection of Mitotane in Tween- 80 and saline was better absorbed and caused greater toxic side effects, both Mitotane and Mitometh were then tested. Doses of 50 and $100 \mathrm{mg} / \mathrm{kg}$ Mitotane or Mitometh were given daily by i.p. injection for 2 weeks. The previously described side effects occurred in all animals but were most severe during treatment with Mitometh. Serum cortisol levels increased dramatically in all treatment groups. Serum drug levels were higher in the Mitometh-treated animals. Mitometh was then formulated in Tween-80, saline, and syrup and was given orally at doses of $75 \mathrm{mg} / \mathrm{kg}$ daily for 4 weeks. The drug was tolerated without toxicity and high blood levels were obtained. Cortisol levels did not change and histologic examination of the adrenal glands failed to reveal any significant adrenalytic effect. In view of the lack of significant suppressive effects on cortisol levels or histologic adrenal changes with either Mitotane or Mitometh in the guinea pig, we switched to male mongrel dogs weighing $12-15 \mathrm{~kg}$ since dogs had been found to be the most sensitive species to the adrenalytic effect of Mitotane [15].

Dogs were treated with Mitotane or Mitometh in sesame oil solution given orally in capsule form. Blood samples were obtained daily for determination of cortisol, $\mathrm{ACTH}$, and drug levels. Biochemical indices of liver function were obtained on the last day of treatment. The treatment was continued for periods of $6-12$ days, and the dogs were adrenalectomized and subsequently euthanized on the day following the last dose. In each experiment, one dog was used as a control and received sesame oil capsules at the same frequency as did the animals receiving the drug.

Samples of adrenal glands and livers were fixed in 10\% neutral buffered formalin and embedded in paraffin. Sections stained with hematoxylin and eosin were evaluated for evidence of tissue damage

In vitro studies. The adrenalytic potential of Mitotane and Mitometh in human adrenal cancer was compared in vitro using a steroid hormonesecreting human adrenocortical carcinoma cell line, NCI H-295 [9]. Cells were maintained at $37^{\circ} \mathrm{C}$ with $5 \% \mathrm{CO}_{2}$ in RPMI 1640 medium supplemented with $5 \mu \mathrm{g}$ insulin from bovine pancreas $/ \mathrm{ml}(24 \mathrm{IU} / \mathrm{ml}), 10 \mu \mathrm{g}$ human transferrin/ml, $2 \mathrm{~mm}$ glutamine, $10 \mathrm{nM}$ hydrocortisone, $10 \mathrm{nM}$ estradiol, $50 \mathrm{nM}$ sodium selenite, 100 units penicillin $/ \mathrm{ml}, 0.1 \mathrm{mg}$ streptomycin $/ \mathrm{ml}, 250 \mathrm{ng}$ amphotericin $\mathrm{B} / \mathrm{ml}$, and $5 \%$ fetal bovine serum. Cells were harvested for subculturing and for experiments using $0.05 \%$ porcine trypsin and $0.02 \%$ ethylenediaminetetraacetic acid (EDTA) in Hank's balanced salt solution. All medium components and trypsin/EDTA were obtained from Sigma Chemical Company (St. Louis, Mo.). For evalua- 

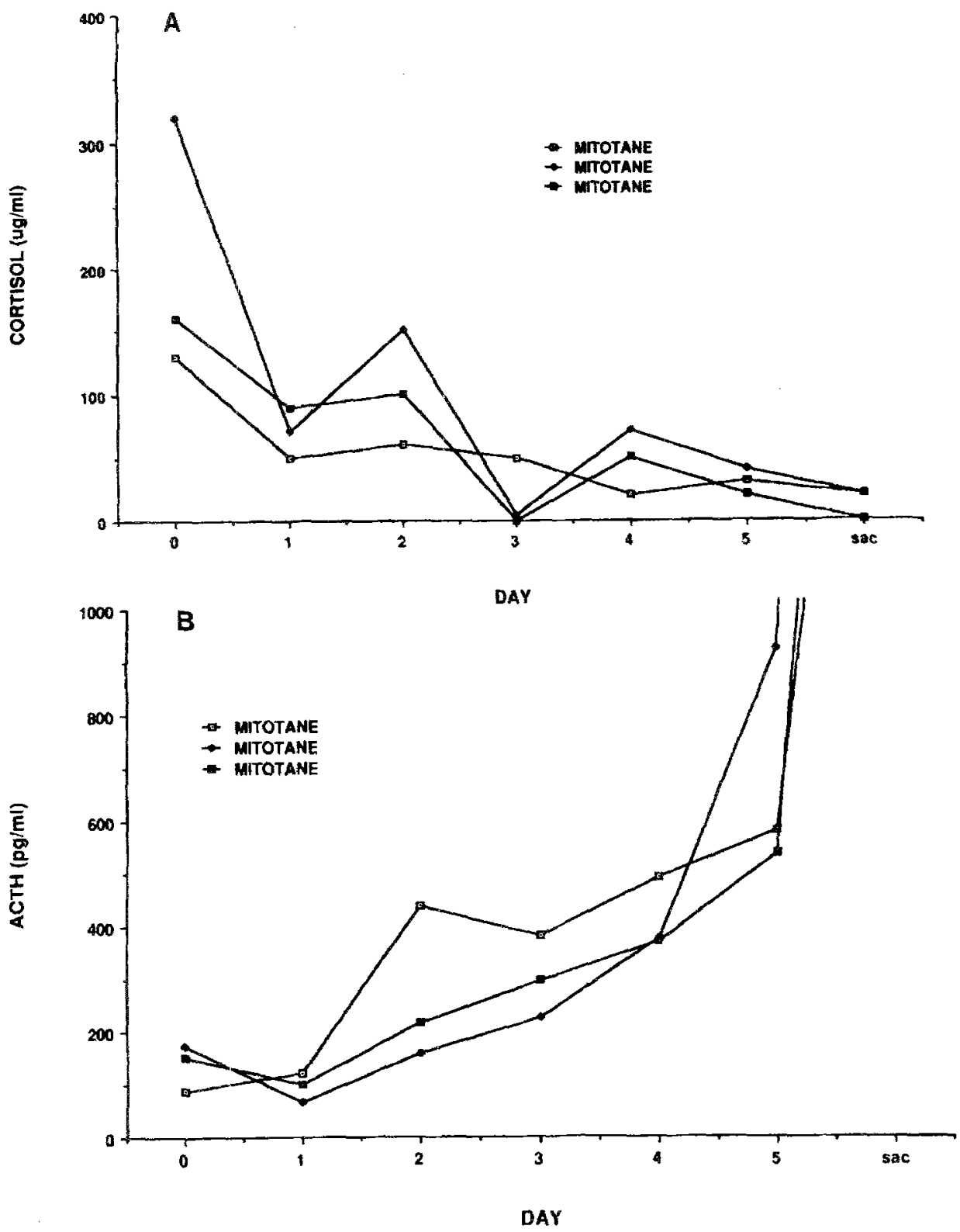

Fig. 2. A Fall in serum cortisol and $B$ rise in plasma ACTH levels in three dogs during treatment with Mitotane at $47 \mathrm{mg} / \mathrm{kg}$ daily for 6 days. Dogs were killed (sac) on the 7th day tion of cell-growth inhibition, 10,000 cells/well were distributed into 96-well plates and incubated for 7 days. Then the drugs were dissolved in ethanol and added to the wells to obtain the desired concentrations. Incubation was continued for an additional 7 days, after which the medium was sampled for determination of cortisol concentration using the assay described above for serum. Cell growth was evaluated by measuring the relative protein content of the cell cultures using the sulforhodamine $B$ assay [26] on the day on which drugs were added and on the 7 th day of drug treatment. The cortisol concentration and the number of cell doublings in wells to which the drugs had been added were expressed as a percentage of the results obtained in control wells in the absence of drug.

\section{Results}

\section{In vivo studies}

Adrenalytic effect. A total of 13 dogs were treated with either Mitotane or Mitometh. Figure $2 \mathrm{~A}$ depicts the fall in cortisol levels during treatment with Mitotane $(47 \mathrm{mg} / \mathrm{kg}$ daily) in three dogs. These levels did not rise at the time of euthanasia in spite of a marked increase in ACTH values. Figure 2B shows that ACTH levels rose steadily throughout the study to 5 times the baseline values, with a large response occurring at the time of euthanasia, consistent with a hypothalamic-pituitary response to stress. Figure 3 compares the response to Mitotane and Mitometh in sesame oil in two dogs treated with these drugs at doses of $47 \mathrm{mg} / \mathrm{kg}$ daily for 6 days. A third dog received the vehicle alone. As depicted in Fig. $3 \mathrm{~A}$, in the dog treated with Mitotane, serum cortisol levels declined steadily over $48 \mathrm{~h}$ and remained at very low levels throughout the study. At the time at which the animals were killed, serum cortisol levels remained suppressed. In contrast, the dog treated with Mitometh maintained cortisol levels in a range similar to that of the control dog. Figure $3 \mathrm{~B}$ depicts the ACTH response during treatment with Mitotane or Mitometh. Whereas the Mitotane-treated dog showed a steady increase in ACTH levels that was simultaneous with the drop 


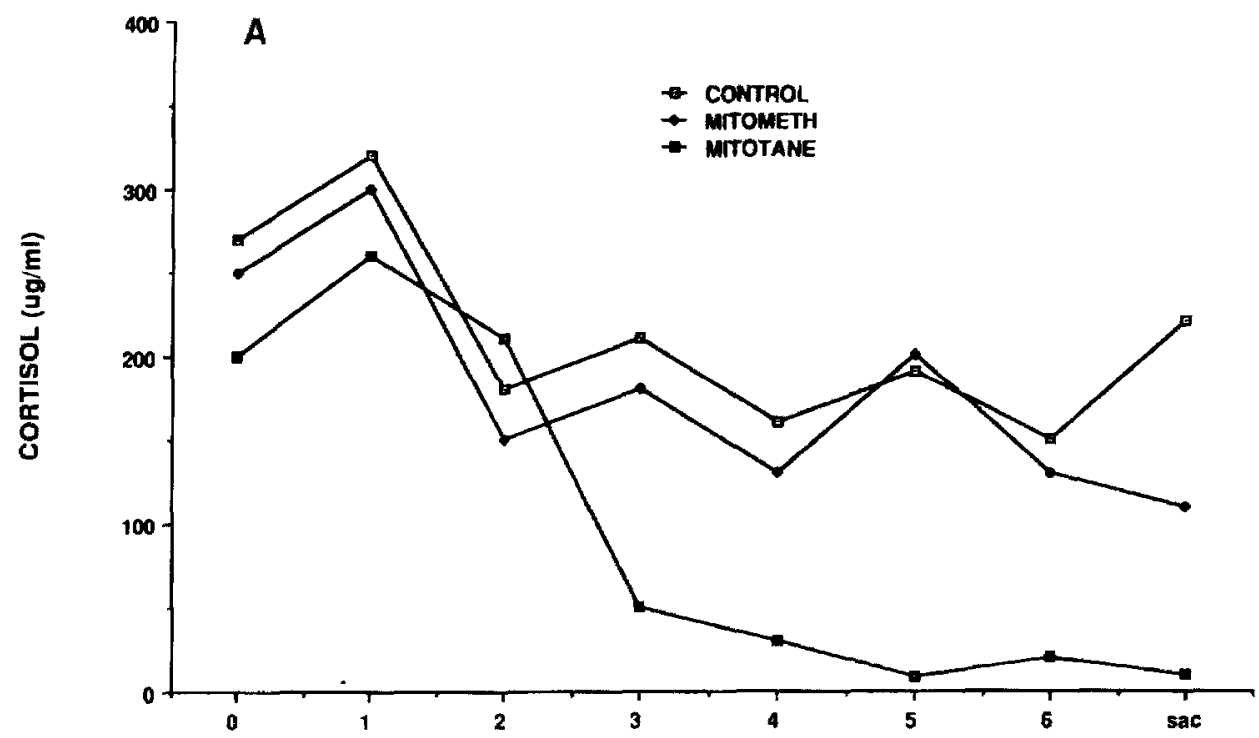

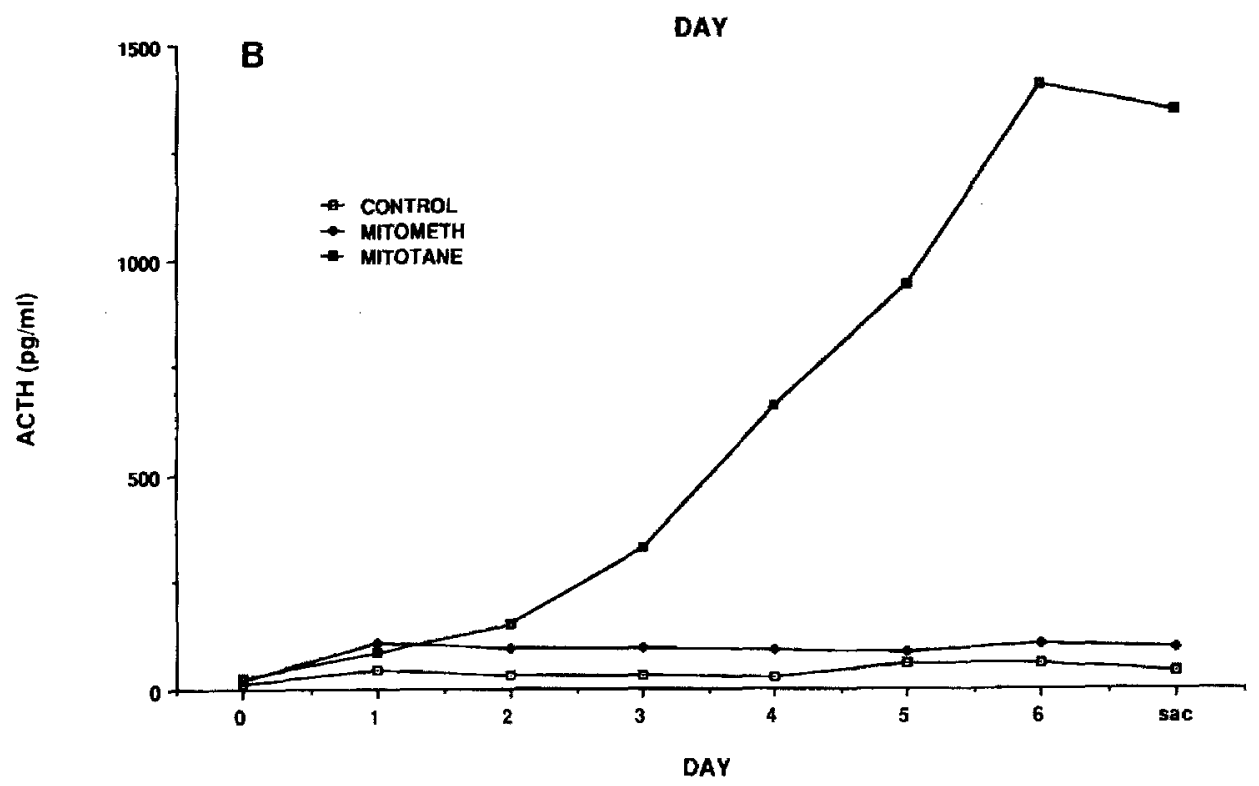

Fig. 3 A, B. Contrast in the A cortisol and $\mathbf{B}$ ACTH response to treatment with Mitotane or Mitometh at $47 \mathrm{mg} / \mathrm{kg}$ daily for 6 days. The control dog received sesame oil capsules. Whereas Mitotane promptly suppressed adrenal function, Mitometh treatment had no significant effect in cortisol and development of adrenocortical insufficiency, the values measured in the Mitometh-treated dog remained at baseline levels throughout the study in a manner similar to that observed for the control dog. In spite of this very different response, blood levels of Mitotane (day $5,4.4 \mu \mathrm{g} / \mathrm{ml}$; day $6,5.9 \mu \mathrm{g} / \mathrm{ml}$ ) and Mitometh (day 5 , $5.3 \mu \mathrm{g} / \mathrm{ml}$; day $6,5.9 \mu \mathrm{g} / \mathrm{ml}$ ) were comparable in the two animals. Additional studies using Mitometh in three dogs at $89 \mathrm{mg} / \mathrm{kg}$ daily for 6 days or in another four dogs at the same daily dose for 12 days failed to change either cortisol or ACTH levels significantly. The drug concentration in the adrenal cortex of these dogs following treatment was also measured. The mean ( \pm SD) Mitometh concentration determined after Mitometh treatment $(171.2 \pm 11.1 \mu \mathrm{g} / \mathrm{g}$ wet weight) was much higher than the Mitotane concentration measured after Mitotane treatment $(69.7 \pm 2.5 \mu \mathrm{g} / \mathrm{g}$ wet weight). The difference in response was therefore not due to differences in blood or tissue drug concentrations.
Figure 4 depicts the histologic changes observed in the adrenal glands of dogs treated with Mitotane or Mitometh as compared with the gland of a control dog (Fig. 4A). Whereas Mitotane treatment was associated with significant necrosis and hemorrhage (Fig. 4B), Mitometh (Fig. 4C) produced no significant histologic effect.

Drug toxicity. Blood samples for measurement of AST, ALT, total cholesterol, and alkaline phosphatase were obtained before and on the last day of drug treatment. In spite of its lack of adrenalytic effect, Mitometh treatment was associated with a decrease in cholesterol and alkaline phosphatase values and a marked increase in SGPT and SGOT levels, consistent with hepatoxicity (Table 1). In contrast, the changes observed during treatment with Mitotane were much milder. Histologic examination of the livers revealed no significant abnormality in the Mitotane- 

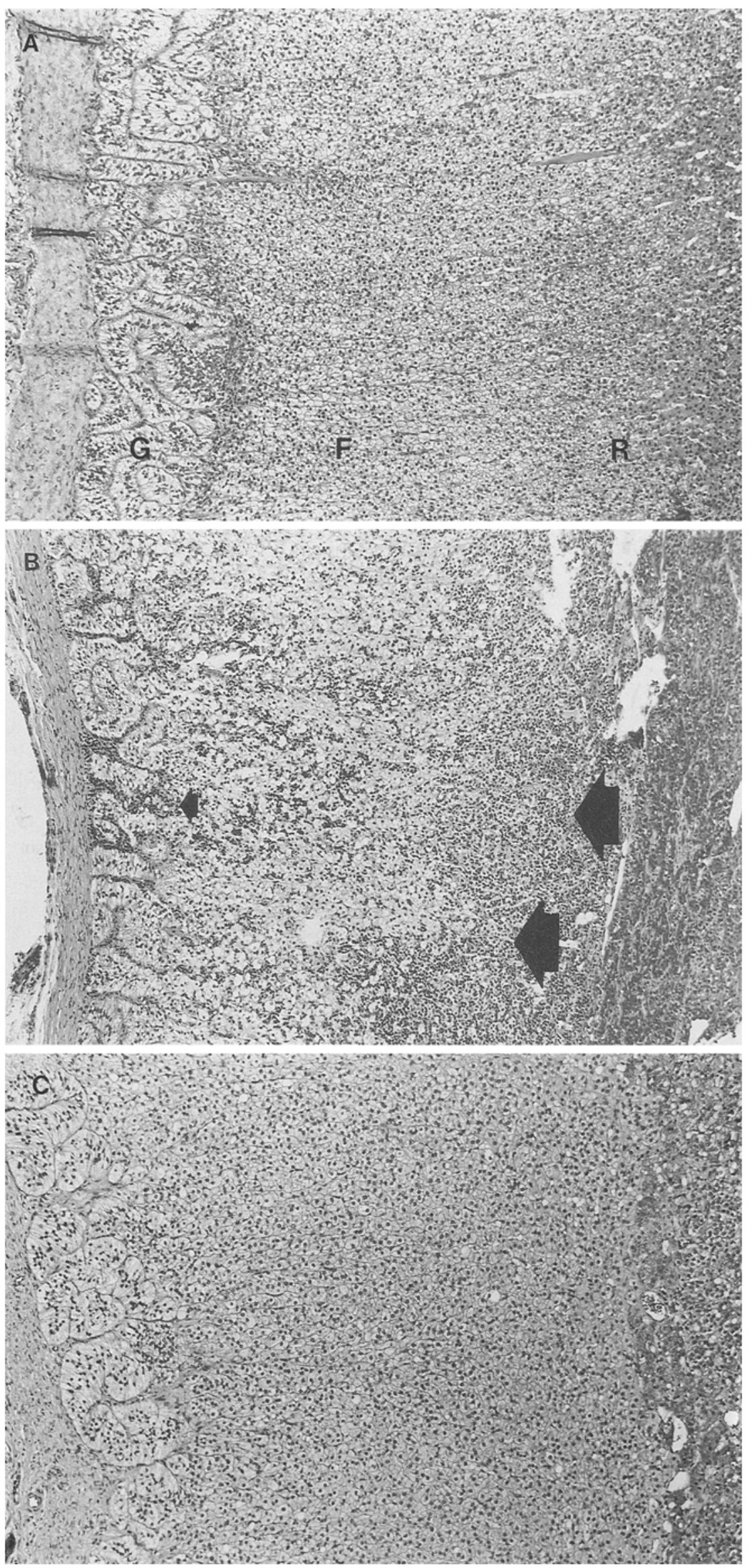

Fig. 4A. Adrenal cortex of a sesame oil-treated control. The capsule is at the left and the medulla, to the right. All zones of the cortex ( $G$, glomerulosa; $F$, fasciculata; $R$, reticularis) are intact and show no evidence of inflammation. Hematoxylin and eosin, $\times 120$. Fig. 4 B. Adrenal cortex of a Mitotanetreated dog, oriented as in Fig. $4 \mathrm{~A}$. Adjacent to the medulla, a dense infiltrate of inflammatory cells (large arrows) is evident in the deep cortex, which has undergone extensive necrosis. Similar dark areas of inflammatory cellular infiltrate (small arrows) also extend toward the capsule. Hematoxylin and eosin, $\times 120$. Fig. 4C. Adrenal cortex of a Mitometh-treated dog, oriented as in Figs. 4A and 4B. All zones of the cortex are intact and show no evidence of damage. Hematoxylin and eosin, $\times 120$ 

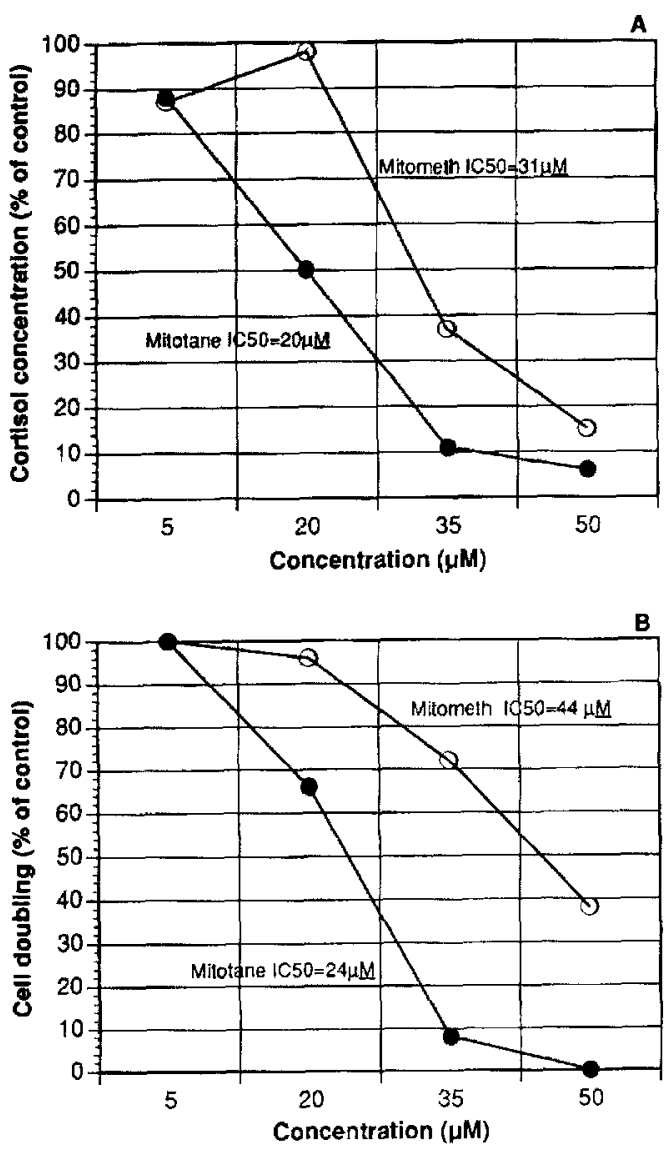

Fig. 5 A, B. Comparison of the inhibition of $\mathbf{A}$ cortisol production and B cell doubling by $5-50 \mu_{\mathrm{M}}$ Mitotane $(O)$ and Mitometh $(O)$ in H-295 cells in vitro. Cells were incubated for 7 days after drug addition, then cortisol concentration and cell doubling were measured. During these 7 days in control cultures, cortisol production resulted in a concentration of $270 \mathrm{~nm}$ in the medium, and the cells doubled 1.5 times. These are average control values. The cortisol concentration and cell doublings in the drug-treated cultures are expressed as a percentage of the control values within each experiment. The values shown are the averages of the values obtained in two independent experiments, which differed by less than $30 \%$. The concentration required to inhibit cortisol production and cell doubling by $50 \%\left(\mathrm{IC}_{50}\right)$ was derived graphically for each drug

treated animals, but, corresponding to the biochemical data in Table 1, the livers of Mitometh-treated dogs showed microvesicular steatosis and spotty hepatocellular necrosis.

\section{In vitro studies}

Figure 5 compares the response of H-295 adrenal cancer cells to Mitotane and Mitometh after a 7-day incubation period. Mitotane had a marked suppressive effect on cortisol concentration (Fig. 5A) and cell doubling (Fig. 5B), affecting both similarly at a $50 \%$ inhibitory concentration (IC 50 ) of 20 and $24 \mu \mathrm{M}$, respectively. Thus, the suppression of cortisol production by Mitotane in vitro can be accounted for by the suppression of cell growth alone without any effect on the amount of cortisol produced per cell. These results are consistent with the conclusion that in the concentration range studied, Mitotane suppresses cell
Table 1. Biochemical side effects of treatment with Mitometh at $89 \mathrm{mg} / \mathrm{kg}$ for 12 days

\begin{tabular}{lrrrrrr}
\hline & Dog 1 & \multicolumn{3}{c}{ Dog 2 } & Dog 3 \\
& B & Rx & B & Rx & B & Rx \\
\hline Cholesterol & 131 & 98 & 153 & 16 & 222 & 67 \\
Alkaline phosphatase & 113 & 1298 & 20 & 936 & 39 & 978 \\
ALT & 25 & 148 & 25 & 279 & 30 & 127 \\
AST & 23 & 65 & 23 & 130 & 15 & 55 \\
\hline
\end{tabular}

B, Baseline; Rx, after drug therapy

growth but does not directly inhibit cortisol synthesis. Mitometh had a similar but consistently weaker (not statistically significant) effect at $\mathrm{IC}_{50}$ values of $31 \mu \mathrm{M}$ for cortisol and $44 \mu \mathrm{M}$ for cell doubling. Interestingly, Mitometh appears to have a direct effect on cortisol production, as it inhibited the cortisol concentration more strongly than it did cell growth.

\section{Discussion}

The studies described herein indicate that contrary to the initial studies by Jensen and co-workers [13], Mitometh does not exert adrenalytic effects in either the guinea pig or the dog. This is in contrast to the well-known adrenalytic effect of its parent compound, Mitotane. The lack of adrenalytic effect was noted in spite of the increased uptake and concentration of Mitometh in the dog adrenal. Since the methylation of Mitotane blocks its ability to undergo transformation to DDA, our findings are in agreement with those proposed by Martz and Straw [15], which suggest that metabolism is required for the adrenalytic effect. As an extension of this hypothesis, our studies indicate that a C-H needs to be preserved at the $\mathrm{C}-2$ position in the aliphatic portion of the molecule. Accordingly, metabolism for Mitotane would involve hydroxylation at C-2 and, following dehydrochlorination, the formation of a transient acyl chloride (Fig. 6) that would be capable of acetylating important macromolecules in the adrenal cortical cell.

Supporting the need of metabolic transformation for activity are studies [15] showing that dog adrenal mitochondria metabolize Mitotane to reactive products that covalently bind to mitochondrial macromolecules. The level of metabolism and covalent binding of [ $\left.{ }^{14} \mathrm{C}\right]$-Mitotane was greater in dog adrenals than in those of the guinea pig, rabbit, or rat, and it correlated with the known sensitivity of these species to the adrenalytic effect of the drug, with the dog being the most sensitive and the rat, the least sensitive species. The relative insensitivity of the guinea pig to $\mathrm{Mi}-$ totane probably explains in part the failure to observe significant adrenalytic effects in this animal model. Another explanation for the lack of response was poor absorption as indicated by undetectable serum drug levels following oral administration. Jensen et al.'s report on the effects of Mitotane and Mitometh did not include measurement of adrenal function or histologic changes on light microscopy. The effects described occurred only at the ultramicroscopic level and were probably very mild. The Mitometh used in 


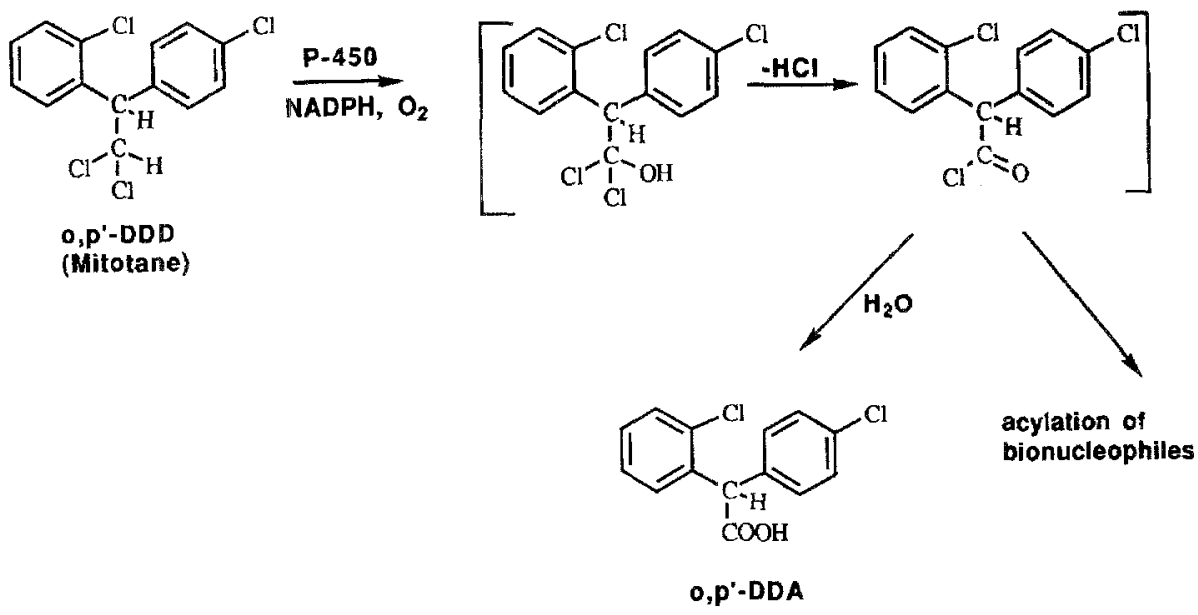

Fig. 6. Postulated metabolic transformation of Mitotane with the formation of an acyl chloride our study was prepared by a modification of the method of Jensen et al. [13], which afforded a crystalline product rather than an oil. Despite recrystallization, the final product contained $2.6 \%$ of the product arising from the dehydrochlorination. Because of the possibility that this unsaturated analog of Mitometh might have been responsible for the results obtained by Jensen et al., dogs were treated with this compound for 6 days without significant adrenalytic effect.

The importance of an intact $\mathrm{C}-\mathrm{H}$ at the $\mathrm{C}-2$ position of the aliphatic portion of the molecule is supported by the experience with 26 DDD analogs previously tested [1-3, $5,6-8,11,14,16-19]$. These studies indicate that cytotoxic adrenal effects are most consistently associated with a dihalogenated ethane structure. The adrenalytic effect of Mitotane is lost if the $\mathrm{H}$ is replaced by a chlorine as in $o, p^{\prime}$-DDT and other trichlorinated analogs of Mitotane [5, 7]. In contrast, substitutions in the benzene rings are less critical in determining adrenalytic effects.

Although the nature of the active metabolites involved and the mechanism by which they exert their adrenalytic effect remains to be defined, studies from our laboratories have demonstrated metabolic oxidation of both the aromatic and the aliphatic portions of Mitotane in rats [21] and in humans [23]. In addition, our in vitro studies have shown aliphatic oxidation in bovine adrenal incubations [22] as well as aromatic hydroxylation and side-chain oxidation in perfusion studies of dog adrenals [25]. It is possible that the mechanism of adrenal cytotoxicity may involve a cytochrome P-450 enzyme-mediated metabolic activation in a process similar to that undergone by other dihalogenated-ethane compounds where acyl halides would be the reactive intermediates. Studies in mice and hamsters suggest this mechanism for the formation of $p, p^{\prime}$-DDA from 1,1-bis ( $p$-chlorophenyl) 2,2-dichloroethane ( $p, p^{\prime}$ DDD) [10]. Another example is the metabolic activation of chloramphenicol (CAP), a compound with partial structural homology with Mitotane. Studies of the metabolic activation of CAP by rat-liver microsomes [20] suggest the involvement of a cytochrome P-450-activating system. The proposed mechanism is that the $\mathrm{C}-\mathrm{H}$ bond of the dichloromethyl carbon is oxidized and the hydroxylated metabolite is spontaneously dehydrochlorinated to produce an oxamyl chloride derivative. This reactive metabolite reacts with microsomal protein to cause cytotoxic effects. A similar mechanism appears to apply to other chlorinated compounds such as halothane and chloroform [4]. Because of the transient nature of the acyl chloride, direct studies to confirm this mechanism have not been forthcoming.

The effect of Mitometh on human adrenal cortical carcinoma cells in vitro is also of interest. Mitometh suppressed both cortisol production and cell doubling. This response differed from the lack of cortisol suppression and adrenalytic effect observed in dogs in vivo. It is unlikely that differences in bioavailability played a role in these different responses since the concentration of Mitometh achieved in the dog adrenals was much higher than that of Mitotane. Other mechanisms may explain this discrepancy. The in vivo studies were conducted in normal dogs, whereas the in vitro studies were carried out in human adrenal cancer cells. These cells may respond to Mitometh by mechanisms that do not require metabolic transformation.

Although Mitotane is effective as an adrenalytic drug, its use is limited by side effects. In a study of 26 patients with pituitary ACTH-dependent Cushing's syndrome treated with cobalt irradiation of the pituitary gland and low-dose Mitotane chemotherapy, we observed [24] that $88 \%$ of the patients developed anorexia and nausea; $38 \%$, diarrhea; and $23 \%$ vomiting. In all, $50 \%$ of the patients complained of neurologic symptoms associated with a decreased in memory and in the ability to concentrate. Skin rashes, arthralgias, and leukopenia were observed in a smaller percentage of patients. There were also a variety of biochemical side effects, including hypercholesterolemia, hypouricemia, and increased liver enzymes. Clearly there is a need for a better drug for the treatment of patients suffering from adrenal cancer. Unfortunately, Jensen et al.'s observations that Mitometh was more adrenalytic and less toxic than Mitotane have not been confirmed in these studies. In fact, toxicity persisted in spite of the lack of adrenalytic effects, and hepatic necrosis during treatment with Mitometh was clearly present. Because of its toxicity and its weak adrenalytic effect on adrenal cancer in vitro, Mitometh is not likely to be of utility in the treatment of adrenal cancer. The present studies provide supporting evidence of the requirement for metabolic transformation at C-2 of Mitotane for the production of adrenalytic effects. 
Acknowledgements. This investigation was supported by grant RO1 CA37 794 from the National Cancer Institute, DHHS, and in part by the In Vitro Drug Evaluation Core of the University of Michigan Comprehensive Cancer Center via grant 2P30 CA46592 from the National Cancer Institute, DHHS.

\section{References}

1. Bleiberg MJ, Larson PS (1957) Studies on derivatives of 2,2 bis-( $p$ chlorophenyl)-1,1-dichloroethane (DDD, TDE) with special reference to their effects on the adrenal cortex. J Pharmacol Exp Ther 121: $421-431$

2. Cobey FA, Taliaferro I, Haag HB (1956) Effect of DDD and some of its derivatives on plasma $17-\mathrm{OH}$ corticosteroids in the dog. Science 123: $140-141$

3. Cobey FA, Taliaferro I, Haag HB (1958) Further observations on effect on plasma 17-OH corticosteroids in the dog of derivatives of 2,2-bis-(p-chlorophenyl)-1,1-dichloroethane (DDD, TDE). Proc Soc Exp Biol Med 97: 491-494

4. Cohen EN, Trudell JR, Edmunds HN, Watson E (1975) Urinary metabolites of halothane in man. Anesthesiology 43: 392-401

5. Copeland MF, Cranmer MF (1974) Effects of $o, p^{\prime}$-DDT on the adrenal gland and hepatic microsomal enzyme system in the beagle dog. Toxicol Appl Pharmacol 27: 1-10

6. Cueto C, Brown JHV, Richardson AP (1958) Biological studies of an adrenocorticolytic agent and the isolation of the active components. Endocrinology 62: $334-339$

7. Fang VS (1979) Cytotoxic activity of 1-(o-chlorophenyl)-1-( $p$ chlorophenyl)-2,2-dichloroethane (Mitotane) and its analogs on feminizing adrenal neoplastic cells in culture. Cancer Res 39: 139- 145

8. Finnegan JK, Henningar GR, Smith RB, Larson PS, Haag HB (1955) Acute and chronic toxicity studies on 2,2-bis-( $p$-ethylphenyl)-1,1dichloroethane (Perthane). Arch Int Pharmacodyn Ther 103: 404-418

9. Gazdar AF, Oie HK, Shackleton CH (1990) Establishment and characterization of a human adrenocortical carcinoma cell line that expresses multiple pathways of steroid biosynthesis. Cancer Res 50: $5488-5496$

10. Gold B, Brunk G (1984) A mechanistic study of the metabolism of 1,1 dichloro-2,2-bis ( $p$-chlorophenyl) ethane (DDD) to 2,2-bis ( $p$ chlorophenyl) acetic acid (DDA). Biochem Pharmacol 33: 979-982

11. Hart M, Reagan RL, Adamson RH (1973) The effect of isomers of DDD on the ACTH-induced steroid output, histology and ultrastructure of the dog adrenal cortex. Toxicol Appl Pharmacol 24: 101-113

12. Hunter WM, Greenwood FC (1987) Preparation of iodine-131 labeled human growth hormone of high specific activity. Nature 194: $495-496$

13. Jensen BL, Caldwell MW, French LG, Briggs DG (1987) Toxicity, ultrastructural effects and metabolic studies with 1-(o-chlorophenyl)- 1-(p-chlorophenyl)-2,2-dichloroethane ( $o, p^{\prime}$-DDD) and its methyl analog in the guinea pig and rat. Toxicol Appl Pharmacol 87: 1-9

14. Larson PS, Hennigan GR, Finnegan JK, Blackwell Smith R, Haag $\mathrm{HB}$ (1955) Observations on the relation of chemical structure to the production of adrenal cortical atrophy or hypertrophy in the dog by derivatives of DDD, TDE. J Pharmacol Exp Ther 115: 408-412

15. Martz F, Straw JA (1980) Metabolism and covalent binding of 1-(o-chlorophenyl)-1-( $p$-chlorophenyl)-2,2-dichloroethane $\left(o, p^{\prime}\right.$ DDD). Correlation between adrenocorticolytic activity and metabolic activation by adrenocortical mitochondria. Drug Metab Dispos 8: $127-130$

16. Nelson AA, Woodard G (1949) Severe adrenal cortical atrophy (cytotoxic) and hepatic damage produced in dogs by feeding 2,2-bis (parachlorophenyl)-1,1-dichloroethane (DDD or TDE). Arch Pathol 48: $387-394$

17. Nichols J (1961) Studies on an adrenal cortical inhibitor. In: Moon HD (ed) The adrenal cortex. Paul B. Hoeber, New York, pp $84-107$

18. Nichols J, Prestley WF, Nichols F (1961) Effects of $m, p^{\prime}$-DDD in a case of adrenal cortical carcinoma (a preliminary report). Curr Ther Res 3: $266-271$

19. Nichols J, Warren JC, Mantz FA (1962) ACTH-like excretion from carcinoma of the ovary. The clinical effects of $m, p^{\prime}$-DDD. JAMA 182: $713-718$

20. Pohl LR, Krishna G (1978) Study of the mechanism of metabolic activation of chloramphenicol by rat liver microsomes. Biochem Pharmacol 27: $335-341$

21. Reif D, Sinsheimer JE (1975 a) Metabolism of 1-(o-chlorophenyl)-1( $p$-chlorophenyl)-2,2 dichloroethane (o, $p^{\prime}$-DDD) in rats. Drug Metab Dispos 3: 15-25

22. Reif VD, Sinsheimer JE (1975b) In vitro biotransformations of $o, p^{\prime}$-DDD and $p, p^{\prime}$-DDD by bovine adrenal. J Agric Food Chem 23: $996-999$

23. Reif VD, Sinsheimer JE, Ward JC, Schteingart DE (1974) Aromatic hydroxylation and alkyl oxidation in the metabolism of Mitotane (o.p'-DDD) in humans. J Pharm Sci 63: 1730-1736

24. Schteingart DE, Tsao HS, Taylor CI, McKenzie AK, Victoria RS, Therrien B (1980) Sustained remission of Cushing's disease with Mitotane and pituitary irradiation. Ann Intern Med 92: 613-619

25. Sinsheimer JE, Freeman CJ (1987) Mitotane [1-(o-chlorophenyl)-1( $p$-chlorophenyl)-2,2-dichloroethane] metabolism in perfusion studies with dog adrenal glands. Drug Metab Dispos 15: 267-269

26. Skehan P, Storeng R, Scudiero D, Monks A, McMahon J, Vistica D, Warren JT, Bokesch H, Kenney S, Boyd MR J (1990) New colorimetric cytotoxicity assay for anticancer-drug screening. J Natl Cancer Inst 82: 1107-1112

27. Vague P, Oliver C, Jaquet P, Vague J (1971) Le dosage radioimmunologique de l'ACTH plasmatique: resultats chez le sujets normaux. Eur J Clin Biol Res 16: 485 -493 